\title{
Assimilation of Simulated Polarimetric Radar Data for a Convective Storm Using the Ensemble Kalman Filter. Part I: Observation Operators for Reflectivity and Polarimetric Variables
}

\author{
YOUNGSUN JunG \\ School of Meteorology, and Center for Analysis and Prediction of Storms, University of Oklahoma, Norman, Oklahoma \\ GUIFU ZHANG \\ School of Meteorology, University of Oklahoma, Norman, Oklahoma \\ Ming Xue \\ School of Meteorology, and Center for Analysis and Prediction of Storms, University of Oklahoma, Norman, Oklahoma
}

(Manuscript received 9 November 2006, in final form 20 November 2007)

\begin{abstract}
A radar simulator for polarimetric radar variables, including reflectivities at horizontal and vertical polarizations, the differential reflectivity, and the specific differential phase, has been developed. This simulator serves as a test bed for developing and testing forward observation operators of polarimetric radar variables that are needed when directly assimilating these variables into storm-scale numerical weather prediction (NWP) models, using either variational or ensemble-based assimilation methods. The simulator takes as input the results of high-resolution NWP model simulations with ice microphysics and produces simulated polarimetric radar data that may also contain simulated errors. It is developed based on calculations of electromagnetic wave propagation and scattering at the $\mathrm{S}$ band of wavelength $10.7 \mathrm{~cm}$ in a hydrometeor-containing atmosphere. The T-matrix method is used for the scattering calculation of raindrops and the Rayleigh scattering approximation is applied to snow and hail particles. The polarimetric variables are expressed as functions of the hydrometeor mixing ratios as well as their corresponding drop size distribution parameters and densities. The presence of wet snow and wet hail in the melting layer is accounted for by using a new, relatively simple melting model that defines the water fraction in the melting snow or hail. The effect of varying density due to the melting snow or hail is also included. Vertical cross sections and profiles of the polarimetric variables for a simulated mature multicellular squall-line system and a supercell storm show that polarimetric signatures of the bright band in the stratiform region and those associated with deep convection are well captured by the simulator.
\end{abstract}

\section{Introduction}

Modern data assimilation (DA) techniques such as $3 \mathrm{D}$ and $4 \mathrm{D}$ variational data assimilation (3DVAR and 4DVAR, respectively), and ensemble Kalman filter (EnKF) methods are able to assimilate observations directly using the forward observation operators that link the model state variables to the observations (Kalnay 2002). The goal of DA is to minimize, subject to the

Corresponding author address: Ming Xue, Center for Analysis and Prediction of Storms, National Weather Center, Suite 2500, 120 David L. Boren Blvd., Norman, OK 73072.

E-mail:mxue@ou.edu constraint of observation uncertainty, the difference between the observations and the analysis projected to the observation space using the observation operator. The forward operators also play the role of observation simulator in the Observing System Simulation Experiments (OSSEs) in generating simulated observations (e.g., Xue et al. 2006). The observation operators can also be used to verify model prediction against indirect, often remote-sensed, observations (e.g., Otkin et al. 2007).

For Doppler weather radars like the Weather Surveillance Radar-1988 Doppler (WSR-88D), the radial velocity and equivalent radar reflectivity factor (hereafter reflectivity) data are the two key measurements 
that can be assimilated into NWP models (e.g., Hu et al. $2006 a, b)$. The observation operators for the radial velocity and reflectivity link the model velocity components to the observed radial velocity and the model hydrometeor fields to the observed reflectivity, respectively (Tong and Xue 2005b; Xue et al. 2006). They also should take into account other effects that are necessary for realistic observations, such as the earth curvature effect or the radar beam pattern (Tong and Xue 2005a; Xue et al. 2006).

For reflectivity, the observation operator also depends on the microphysical parameterization schemes used in the NWP model. Smith et al. (1975), Smith (1984), Ferrier (1994), Caumont et al. (2006), and Haase and Crewell (2000) all offer formulas that calculate reflectivity from liquid and ice phase hydrometeors present in bulk microphysics schemes. Various assumptions on the drop size distributions (DSDs) and shapes of liquid and ice particles, radar beam pattern and wavelength, and the way that backscattering cross sections are computed are involved in developing those formulas for radar simulators. Some methods are more sophisticated and computationally expensive than others. Among them, Caumont et al. (2006) developed the most general simulator with various options for X-, C-, and S-band radars based on Rayleigh, Rayleigh-Gans, Mie, and T-matrix scattering methods. However, no continuous melting process is considered in these simulators except for Ferrier (1994), which uses the mixing ratios of liquid water on wet precipitation particles that are predicted in the forecast model. May et al. (2007) is a pulse-based radar emulator that emphasizes the simulation of radial velocity and its spectral width.

Even though reflectivity and radial velocity measurements provide key information on convective storms, they are not sufficient to fully describe microphysical states. One of the reasons is that the number of observations is usually much smaller than the degrees of freedom of the forecast model or even the microphysics model alone. This means that we need to determine more model variables with fewer number of observations. The other reason has to do with many uncertainties in the bulk microphysics schemes. The microphysics represents one of the most important physical processes at the convective scale. The microphysical processes depend to a large extent on the phase, shape, orientation, density, and DSDs of microphysical species involved, many of which are not fully understood. These properties also directly affect radar measurements within each radar sampling volume. Additional observational parameters available from polarimetric Doppler radars, including differential reflectivity and differential phase measurements can be very helpful here as they contain information about the density, shape, orientation, and DSDs of hydrometeors (Doviak and Zrnic 1993; Bringi and Chandrasekar 2001).

Some polarimetric radar simulators already exist in the literature (Brandes et al. 1995, 2004a; Zhang et al. 2001; Vivekanandan et al. 1994; Ryzhkov et al. 1998; Huang et al. 2005). However, they are either incomplete in terms of utilizing all available model parameters and state variables or are too expensive for use within DA systems. Within a DA system, the simulation needs to be performed for each observation, and repeated within a variational minimization scheme. Some of the previous studies have focused on singlephase hydrometeor concentration. Brandes et al. (1995, 2004a) and Zhang et al. (2001) offer the expressions for rain. Vivekanandan et al. (1994) and Ryzhkov et al. (1998) propose formulas that can be applied to ice particles ranging from ice crystals to snow aggregates. Because of the lack of sufficient understanding of the polarimetric measurements for ice and mixed phases because of their complex behaviors and nonlinear interactions, general expressions that are applicable to each of the hydrometeor categories are generally unavailable. More recently, Huang et al. (2005) proposed a more complete polarimetric radar simulator in which a full radar scattering model is used to simulate polarimetric radar signatures from the data of a modelsimulated storm. Such simulators are, however, too expensive for DA use.

In this study, we develop a set of the observation operators consistent with a commonly used three-ice microphysics scheme. The polarimetric variables include reflectivities at the horizontal $\left(Z_{H}\right)$ and vertical $\left(Z_{V}\right)$ polarizations, differential reflectivity $\left(Z_{\mathrm{DR}}\right)$, reflectivity difference $\left(Z_{\mathrm{dp}}\right)$, and specific differential phase $\left(K_{\mathrm{DP}}\right)$. These operators are applicable to the $\mathrm{S}$ band radar at about $10.7 \mathrm{~cm}$ of wavelength and can be extended in the future to possibly include additional parameters such as the correlation coefficient $\rho_{\mathrm{hv}}(0)$ and for other wavelengths. Having such a system of our own enables us to adjust and enhance the simulator to fit our data assimilation needs, and in response to the changes with the microphysics parameterization used in the assimilation and prediction model. In fact, these operators are used in Jung et al. (2008, hereafter Part II) to test the impact of simulated polarimetric observations on the storm analysis.

In section 2, the prediction model used to create the simulation datasets is briefly described. The forward observation operators for the polarimetric radar variables associated with microphysics schemes with varying degrees of assumptions are then developed in sec- 
tion 3. These observational operators are then applied to a simulated squall line and a supercell storm in section 4. Conclusions and a discussion are given in section 5 .

\section{The model and convective storm simulations}

The Advanced Regional Prediction System (ARPS; Xue et al. 2000, 2001, 2003) is used to produce convective storm simulations, of a squall and a supercell, that are used to test our radar emulator. The reflectivityrelated formulas are also closely related to the microphysics scheme used in the model. Briefly, ARPS is a fully compressible and nonhydrostatic atmospheric prediction model. The model state vector consists of three velocity components $u, v$, and $w$; potential temperature $\theta$; pressure $p$; and the mixing ratios for water vapor, cloud water, rainwater, cloud ice, snow aggregate, and hail $\left(q_{v}, q_{c}, q_{r}, q_{i}, q_{s}\right.$, and $q_{h}$, respectively) when the ice microphysics scheme based on Lin et al. (1983, hereafter LFO83) is used. The model also predicts the turbulence kinetic energy, which is used by the 1.5-order subgrid-scale turbulence closure scheme.

An idealized two-dimensional squall-line system is initiated by a $4-\mathrm{K}$ ellipsoidal thermal bubble with a 10 $\mathrm{km}$ horizontal radius and a $1.4-\mathrm{km}$ vertical radius, and the bubble is centered at $x=400 \mathrm{~km}$ and $z=1.4 \mathrm{~km}$ in the $700 \times 19.2 \mathrm{~km}^{2}$ physical domain. The horizontal grid spacing is $200 \mathrm{~m}$ and the vertical grid has a uniform 100 -m grid spacing in the lowest $3 \mathrm{~km}$, which then increases to $853 \mathrm{~m}$ at the model top. The simulation is run for $12 \mathrm{~h}$ with the analytic thermodynamic sounding defined by Weisman and Klemp (1982), where the potential temperature and temperature are 343 and $213 \mathrm{~K}$, respectively, at the $12-\mathrm{km}$-high tropopause, and the surface potential temperature is $300 \mathrm{~K}$. The mixed-layer mixing ratio is $15 \mathrm{~g} \mathrm{~kg}^{-1}$, the upper limit of relative humidity is $95 \%$, and the mixed layer depth is $1.2 \mathrm{~km}$. The environmental wind profile has a constant shear of $17.5 \mathrm{~m} \mathrm{~s}^{-1}$ in the lowest $2.5 \mathrm{~km}$ and a constant wind speed of $-2.5 \mathrm{~m} \mathrm{~s}^{-1}$ above $2.5 \mathrm{~km}$. These configurations are similar to those used in Xue (2002), with the main differences being the wind profile and horizontal resolution. This specified environmental condition generally supports long-lived squall lines that sometimes develop a trailing stratiform precipitation region (Thorpe et al. 1982; Rotunno et al. 1988).

For a more intense, isolated supercell storm simulation, ARPS is initialized with the environmental sounding of the 20 May 1977 Del City, Oklahoma, supercell storm (Ray et al. 1981). The CAPE of the sounding is $3300 \mathrm{~J} \mathrm{~kg}^{-1}$ and the storm is initiated by an ellipsoidal thermal bubble with the same characteristics as that of the squall-line case except for a vertical radius of 1.5 $\mathrm{km}$. The bubble is centered at $x=48 \mathrm{~km}, y=16 \mathrm{~km}$, and $z=1.4 \mathrm{~km}$. The physical domain is $64 \times 64 \times 16$ $\mathrm{km}^{3}$ with a horizontal spacing of $2 \mathrm{~km}$ and a vertical separation of $0.5 \mathrm{~km}$. Open conditions are used at the lateral boundaries and free-slip conditions at the top and bottom of the domain. A constant wind of $u=3$ $\mathrm{m} \mathrm{s}^{-1}$ and $v=14 \mathrm{~m} \mathrm{~s}^{-1}$ is subtracted from the original sounding to keep the storm near the center of the domain. These configurations are essentially the same as in the truth simulation of Tong and Xue (2005b), which also briefly describes the initial evolution of the simulated storm. This simulation serves as the truth simulation for the polarimetric data assimilation experiments in Part II. A polarimetric WSR-88D radar is assumed at the southwest corner of the domain, the same location as that assumed in Tong and Xue (2005b).

\section{The observation operators and simulation of observations}

As discussed earlier, a set of forward observation operators that link model state variables with the polarimetric radar variables is required to assimilate the latter into a numerical model. These operators, together with the radar-scanning configurations, ray path, and beam pattern weighting, make up a complete radar simulator. This paper focuses on the observation operator development. For these operators, a consistency is maintained between the DSD-related parameters of hydrometeors within the operators and within the prediction model. The specific polarimetric radar variables to be considered include reflectivity, differential reflectivity, reflectivity difference, and specific differential phase.

\section{a. The shape, orientation, and drop size distribution of hydrometeors}

The model state variables are projected into the observation space using the observation operators. In this study, we assume that radar observations are taken and available on the original radar elevation levels vertically but are already interpolated onto horizontal model grids, as is done in Xue et al. (2006), which describes the power-gain-based sampling method used in the vertical direction in detail. In the single-moment bulk ice microphysics scheme of LFO83 used in the ARPS, a constant density is assumed for each species and the DSDs of the species are modeled by exponential distributions with fixed intercept parameters $\left(N_{0}\right)$ and variable slopes $(\Lambda)$. In practice, the slope $\Lambda$ for each species is diagnosed from the corresponding speci- 
fied intercept parameter and the predicted mixing ratio. The intercept parameters for rain, snow, and hail used in this study are the default values of $N_{0 r}=8 \times 10^{6}$ $\mathrm{m}^{-4}, N_{0 s}=3 \times 10^{6} \mathrm{~m}^{-4}$, and $N_{0 h}=4 \times 10^{4} \mathrm{~m}^{-4}$ (LFO83).

Additional characteristics that affect the radar observables include the shape, orientation, and the ice/ water fraction of hydrometeors. Unfortunately, these characteristics are not specified or predicted by the model; therefore, assumptions have to be made. Observations show that larger raindrops $(>1 \mathrm{~mm}$ in diameter) are not spherical. Raindrops are normally modeled as oblate spheroids and the oblateness, $r$, is represented by the axis ratio between minor to major axis, which is related to the equivalent diameter $D$ given by Green (1975) in an equilibrium model. After solving the equilibrium equation and fitting to a polynomial function, Zhang et al. (2001) obtained

$$
\begin{aligned}
r= & 1.0148-2.0465 \times 10^{-2} D-2.0048 \times 10^{-2} D^{2} \\
& +3.095 \times 10^{-3} D^{3}-1.453 \times 10^{-4} D^{4}
\end{aligned}
$$

where $D$ is in millimeters. This axis ratio relation has recently been revised based on observations (Brandes et al. 2002), yielding more spherical shapes for smaller drops $(1<D<4 \mathrm{~mm})$. The potential errors associated with more oblate shapes are about $0.15 \mathrm{~dB} Z$ and $0.2 \mathrm{~dB}$ for $Z_{H}$ and $Z_{\mathrm{DR}}$, respectively, in terms of averaged values (Brandes et al. 2002). However, the revised formula requires the numerical integration over the DSD in the scattering calculations, which significantly increases computational cost while the former allows for analytical integration. Although the revised axis ratio is important in the quantitative precipitation estimation for light rain with many small drops, it is not crucial for assimilation purposes. Also, there is no accepted theory that explains the revised axis ratio relation. Therefore, we use the equilibrium shape in (1) in this study. We also assume that the mean and the standard deviation (SD) of the canting angle are $0^{\circ}$, as suggested by observations (Hendry and McCormick 1976), although some observational and theoretical studies suggest that the standard deviation of the canting angles of rain drops is likely not $0^{\circ}$ but less than $10^{\circ}$ (Beard and Jameson 1983; Bringi and Chandrasekar 2001; Ryzhkov et al. 2002). Assuming $0^{\circ} \mathrm{SD}$ can lead to the overestimation of $K_{\mathrm{DP}}$ and $Z_{\mathrm{DR}}$ by less than $6 \%$, this could be tolerated considering the large uncertainties in DSD (Ryzhkov et al. 2002).

The shape of snow can vary greatly in range/complexity and can be modeled as oblate to prolate spheroids. Nevertheless, in the simplest form, they can be approximated to fall with the major axis aligned horizontally (Straka et al. 2000). The mean canting angle of snow aggregates is assumed to be $0^{\circ}$ and the SD of the canting angle is assumed to be $20^{\circ}$ in this study. A fixed axis ratio of 0.75 for snow is used for the scattering calculation. Also, a fixed density of $100 \mathrm{~kg} \mathrm{~m}^{-3}$ is assumed for dry snow aggregates, consistent with the model parameterization.

Hailstones are observed in many different shapes and the orientation of falling hail is not understood precisely. Yet, ground observations suggest that the majority of hailstones have axis ratios of 0.8 with spongy hail having a lower axis ratio of 0.6-0.8 (Knight 1986; Matson and Huggins 1980) and usually wobble and tumble while they fall. Dry hailstones are considered to have random orientations. Therefore, we assume that the axis ratio of hailstones is 0.75 and hailstones fall with their major axes aligned horizontally with a mean canting angle of $0^{\circ}$, although some studies (Aydin and Zhao 1990; Vivekanandan et al. 1993) use other canting angles that are not widely used. As a hailstone melts while falling, meltwater forms a torus around the equator and stabilizes these wobbling and tumbling motions. The SD (or $\sigma$ ) of the canting angle is therefore parameterized as a function of the fractional water content in melting hail, according to $\sigma=60^{\circ}\left(1-c f_{w}\right)$, where $f_{w}$ is the water fraction within water-hail mixtures (see more later) and $c$ is a coefficient equaling 0.8 except for very low mixing ratios of the mixture $\left(q_{\mathrm{rh}}\right)$. This allows dry (wet) hailstones to have large (small) SD of the canting angles.

When the hail mixing ratio is low, we expect more small hail, therefore more spherically shaped particles, leading to smaller $Z_{\mathrm{DR}}$. A fixed axis ratio, assumed in our model, can lead to high $Z_{\mathrm{DR}}$ for low hail mixing ratio when hail is in the melting phase. To take into account the size dependence of the axis ratio, we set a critical value of $q_{\mathrm{rh}}\left(0.2 \mathrm{~g} \mathrm{~kg}^{-1}\right)$, below which the constant $c$ is decreasing as a function of $q_{\mathrm{rh}}$, thus, effectively reducing $Z_{\mathrm{DR}}$. This gives the same effect by assuming more spherical hail for low hail mixing ratios. When $q_{\mathrm{rh}}<0.2 \mathrm{~g} \mathrm{~kg}^{-1}$, it is therefore assumed that $c=4 q_{\mathrm{rh}}$. As in the ARPS model, the hail is assumed to have a fixed density of $913 \mathrm{~kg} \mathrm{~m}^{-3}$. Our hail model, although different in configuration, is consistent with observed Oklahoma hailstones, which show a general trend of decrease in axis ratio with increasing size until reaching a value of about 0.75 (Knight 1986).

\section{b. Melting ice (snow-hail) model}

As the snow aggregate melts, the water forms a thin layer on the surface of snow aggregate and/or distrib- 
utes either evenly or nonuniformly within the snow aggregate, effectively forming a snow aggregate-liquid water mixture, where the snow aggregate itself is a mixture of solid ice and air. We allow continuous melting of low-density dry snow to rain in the melting layer where both rain and snow mixing ratios are nonzero. We denote the mixing ratio of the rain-snow mixture as $q_{\mathrm{rs}}$. Within $q_{\mathrm{rs}}$ a fraction $f_{w}$ is water and a fraction $f_{s}$ is snow and, of course, $f_{w}+f_{s}=1$. However, as with most microphysics schemes in use today, the LFO83 microphysics scheme used in the ARPS does not allow or track species in the mixture form. For example, the melted part of the snow aggregate is immediately removed from $q_{s}$ and added to $q_{r}$. Therefore, the amount and composition of mixture-form species have to be modeled in a way that allows for realistic radar observation simulations.

In this study, we model the rain-snow mixture in the following way. First, as mentioned earlier, the mixture is assumed to exist only when $q_{s}$ and $q_{r}$ coexist. We assume that the fraction of rain-snow mixture reaches a maximum when the snow and water mixing ratios are equal and decreases to zero when one of the two vanishes. Furthermore, we assume this fraction, denoted as $F$, is the same for snow aggregates and rainwater. The fraction $F$ is then given by

$$
F=F_{\max }\left[\min \left(q_{s} / q_{r}, q_{r} / q_{s}\right)\right]^{0.3},
$$

where $F_{\max }$ is the maximum fraction of snow or rainwater mixing ratio existing in the mixture form, or the maximum value of $F$. In this paper, we set $F_{\max }=0.5$. A power of 0.3 is taken of $\min \left(q_{s} / q_{r}, q_{r} / q_{s}\right)$. In the case that $q_{s}$ decreases linearly downward and rainwater increases linearly upward through the melting layer, the $F$ profile has a bracelike shape, with its value peaking near the middle of the melting layer where $q_{s}=q_{r}$; otherwise, the function has a triangular shape with an apex in the middle. With more realistic modelsimulated profiles of mixing ratios, this gives parabolically shaped profiles of mixtures, which is reasonable (thick dashed lines in Figs. 5a and 6a).

Once $F$ is determined, the mixing ratio of rainwater in the mixture form is then $F q_{r}$, and that in the pure water form is $(1-F) q_{r}$. For snow aggregates, the corresponding mixing ratios are $F q_{s}$ and $(1-F) q_{s}$. The total mixing ratio of the mixture is then $q_{\mathrm{rs}}=F\left(q_{r}+q_{s}\right)$ and within this mixture, the water fraction is

$$
f_{w}=\left(F q_{r}\right) /\left(F q_{r}+F q_{s}\right)=q_{r} /\left(q_{r}+q_{s}\right) .
$$

According to (3), the water fraction $\left(f_{w}\right)$ within the snow-water mixture increases from 0 to 1 as snow completely melts after descending through the melting layer while $f_{s}$ decreases from 1 to 0 ; this behavior is reasonable.

A fixed density of $100 \mathrm{~kg} \mathrm{~m}^{-3}$ is assumed for the dry snow aggregate. However, the snow aggregate density varies during melting. The density of wet snow aggregates increases from 100 to $1000 \mathrm{~kg} \mathrm{~m}^{-3}$ as the fraction of the melted portion increases from 0 to 1 . At the very early stage of melting, the size of the snow aggregate does not change much with increasing $f_{w}$ so that the density increases slowly. As melting progresses, $f_{w}$ further increases, the snow particle collapses inducing the shrinkage of the particle, and the density increases more rapidly. To simulate this melting process as the snow aggregate particles descend, the density of the melting snow aggregate is parameterized as a quadratic function of $f_{w}$ :

$$
\rho_{m}=\rho_{s}\left(1-f_{w}^{2}\right)+\rho_{w} f_{w}^{2},
$$

which is used in our reflectivity calculations.

A dry snow aggregate is a mixture of air and ice whose density is $913 \mathrm{~kg} \mathrm{~m}^{-3}$ and a melting snow aggregate is a mixture of air, ice, and water. The dielectric constant for the melting snow aggregate is calculated with a two-step procedure using the Maxwell-Garnett mixing formula (Maxwell-Garnett 1904). In the first step, the ice is considered within the enclosure of air. Because it is reasonable to assume that the melting starts from the surface of the ice particle, the air-ice mixture (snow aggregate) is considered within the enclosure of meltwater in the second step.

A similar melting model is used for hail with the corresponding density and dielectric constant for hail. The density of wet hail increases from 913 to $1000 \mathrm{~kg}$ $\mathrm{m}^{-3}$. The dielectric constant for melting hail is calculated with the ice in the water matrix.

\section{c. Observation operators}

Reflectivities in linear scale at horizontal $\left(Z_{h}\right)$ and vertical $\left(Z_{v}\right)$ polarizations are obtained as integrations over the DSD weighted by the scattering cross section depending on density, shape, and DSD. For rain, dry snow, dry hail, rain-snow mixture, and rain-hail mixture, we have (Zhang et al. 2001) the following:

$$
\begin{aligned}
Z_{h, x}= & \frac{4 \lambda^{4}}{\pi^{4}\left|K_{w}\right|^{2}} \int n(D)\left(A\left|f_{a}\right|^{2}+B\left|f_{b}\right|^{2}\right. \\
& \left.+2 C\left|f_{a}\right|\left|f_{b}\right|\right) d D\left(\mathrm{~mm}^{6} \mathrm{~m}^{-3}\right) \text { and } \\
Z_{v, x}= & \frac{4 \lambda^{4}}{\pi^{4}\left|K_{w}\right|^{2}} \int n(D)\left(B\left|f_{a}\right|^{2}+A\left|f_{b}\right|^{2}\right. \\
& \left.+2 C\left|f_{a}\right|\left|f_{b}\right|\right) d D\left(\mathrm{~mm}^{6} \mathrm{~m}^{-3}\right),
\end{aligned}
$$


(a)

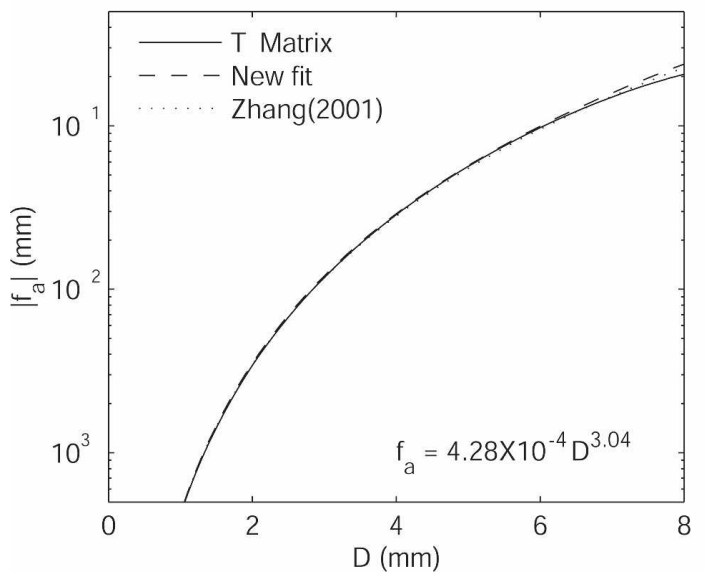

(b)

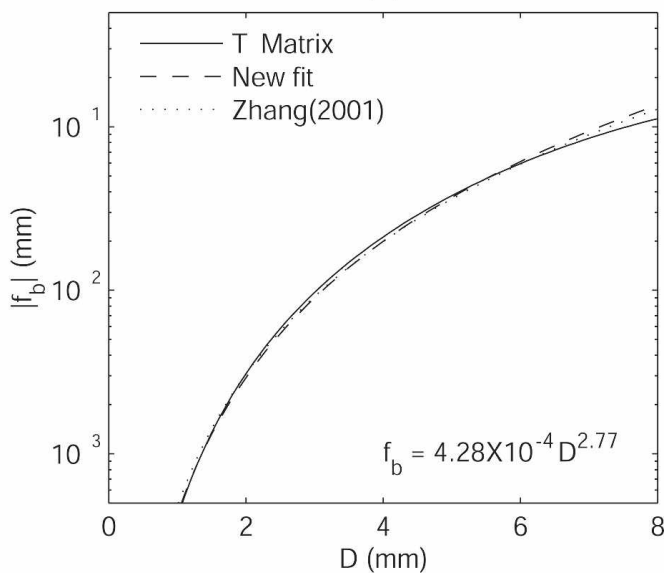

FIG. 1. Backscattering amplitudes as a function of the effective diameter of particles along (a) the major axis and (b) the minor axis.

where

$$
\begin{aligned}
& A=\left\langle\cos ^{4} \phi\right\rangle=\frac{1}{8}\left(3+4 \cos 2 \bar{\phi} e^{-2 \sigma^{2}}+\cos 4 \bar{\phi} e^{-8 \sigma^{2}}\right), \\
& B=\left\langle\sin ^{4} \phi\right\rangle=\frac{1}{8}\left(3-4 \cos 2 \bar{\phi} e^{-2 \sigma^{2}}+\cos 4 \bar{\phi} e^{-8 \sigma^{2}}\right),
\end{aligned}
$$

and

$$
C=\left\langle\sin ^{2} \phi \cos ^{2} \phi\right\rangle=\frac{1}{8}\left(1-\cos 4 \bar{\phi} e^{-8 \sigma^{2}}\right),
$$

and $x$ can be $r$ (rain) and rs (rain-snow mixture), ds (dry snow), rh (rain-hail mixture), or dh (dry hail). Here $f_{a}$ and $f_{b}$ are backscattering amplitudes for polarizations along the major and minor axes, respectively. Here $\bar{\phi}$ is the mean canting angle and $\sigma$ is the standard deviation of the canting angle. As defined in section $3 \mathrm{a}, \bar{\phi}=0^{\circ}$ is assumed for all hydrometeor types and $\sigma=20^{\circ}$ for snow and $\sigma=60^{\circ}\left(1-c f_{w}\right)$ for hail. Here $c=0.8$, where $q_{\mathrm{rh}} \geq 0.2 \mathrm{~g} \mathrm{~kg}^{-1}$ and $c=4 q_{\mathrm{rh}}$ otherwise. The latter is to make the hail shape more spherical for low mixing ratios, as discussed in section 3a. Here $\langle\ldots\rangle$ represents an ensemble average over canting angles and $n(D)$ defines the DSD and is the number of particles per unit volume of air and increment diameter.

Integration over DSD can be easily performed if the backscattering amplitudes are expressed in the powerlaw form of the particle size $D(\mathrm{~mm})$ :

$$
\begin{aligned}
& \left|f_{a}\right|=\alpha_{x a} D^{\beta_{x a}}(\mathrm{~mm}) \quad \text { and } \\
& \left|f_{b}\right|=\alpha_{x b} D^{\beta_{x b}}(\mathrm{~mm}) .
\end{aligned}
$$

Here $\left|f_{a}\right|$ and $\left|f_{b}\right|$ are the magnitudes of $f_{a}$ and $f_{b}$, respectively.

For rain, we first calculate the scattering amplitude of oblate raindrops with the dielectric constant of water evaluated at $10^{\circ} \mathrm{C}$ based on the T-matrix method fol- lowing Zhang et al. (2001). We perform a new fitting because their coefficients produce negative differential reflectivity for small drops. The scattering amplitudes from the $T$ matrix and the fitting results are plotted in Fig. 1. New fits generally agree well with those in Zhang et al. (2001) and with the T-matrix results over the entire range, except for the slightly larger values at the larger drop end. In (7) and (8), $\alpha_{r a}=\alpha_{r b}=4.28 \times 10^{-4}$, $\beta_{r a}=3.04$, and $\beta_{r b}=2.77$ for rain are adopted from the T-matrix calculation and fitting results.

For snow and hail, we calculate the scattering amplitudes as a function of the dielectric constant, which is a function of $f_{w}$, and fit the results to the power-law functions given in (7) and (8). The resultant $\alpha_{s}$ and $\alpha_{h}$ for snow and hail are obtained based on the Rayleigh scattering approximation for oblate spheroids, and fitted to polynomial functions of $f_{w}$ :

$$
\begin{aligned}
\alpha_{\mathrm{rs} a}= & \left(0.194+7.094 f_{w}+2.135 f_{w}^{2}-5.225 f_{w}^{3}\right) \times 10^{-4}, \\
\alpha_{\mathrm{rs} b}= & \left(0.191+6.916 f_{w}-2.841 f_{w}^{2}-1.160 f_{w}^{3}\right) \times 10^{-4}, \\
\alpha_{\mathrm{rh} a}= & \left(0.191+2.39 f_{w}-12.57 f_{w}^{2}+38.71 f_{w}^{3}-65.53 f_{w}^{4}\right. \\
& \left.+56.16 f_{w}^{5}-18.98 f_{w}^{6}\right) \times 10^{-3}, \quad \text { and } \\
\alpha_{\mathrm{rh} b}= & \left(0.165+1.72 f_{w}-9.92 f_{w}^{2}+32.15 f_{w}^{3}-56.0 f_{w}^{4}\right. \\
& \left.+48.83 f_{w}^{5}-16.69 f_{w}^{6}\right) \times 10^{-3} .
\end{aligned}
$$

The $\beta_{s}$ for snow and $\beta_{h}$ for hail are equal to 3 at both polarizations. The equations in (9) give $\alpha_{\mathrm{ds} a}=0.194 \times$ $10^{-4}$ and $\alpha_{\mathrm{ds} b}=0.191 \times 10^{-4}$ for dry snow, and $\alpha_{\mathrm{dh} a}=$ $0.191 \times 10^{-3}$ and $\alpha_{\mathrm{dh} b}=0.165 \times 10^{-3}$ for dry hail. The scattering amplitudes from Rayleigh scattering approximation and the fitting results as a function of $f_{w}$ are plotted in Fig. 2. As discussed in section 3b, melting is 

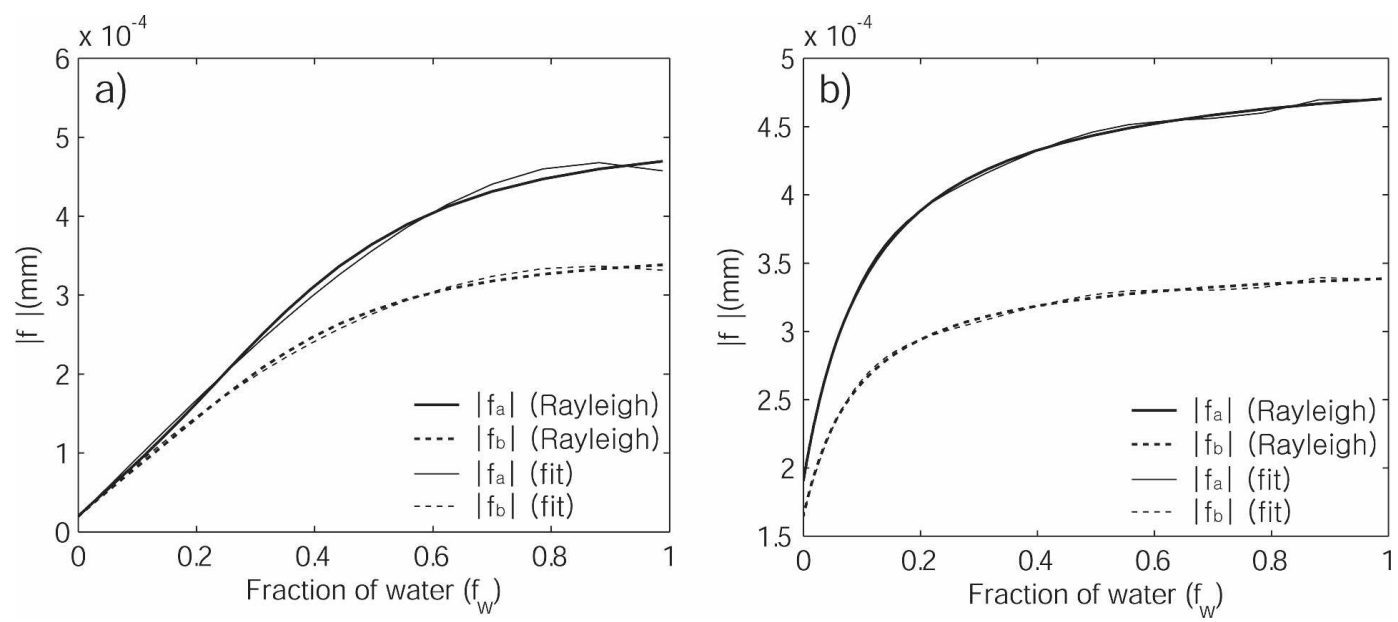

FIG. 2. Backscattering amplitudes as a function of the fraction of water within the mixture along the major axis (solid) and the minor axis (dashed) for the (a) rain-snow and (b) rain-hail mixtures.

likely to start from the surface so that the backscattering amplitude increases more rapidly in the early stage of melting and the slope gradually decreases. Snow shows a lower slope for the low fraction of water than that of hail. This is consistent with our density model given in (4).

In the current study, the non-Rayleigh scattering effect, which is known to be important for large hailstones with a diameter larger than $10 \mathrm{~mm}$ for a S-band radar, is neglected because of the high computational demand by the T-matrix calculation. Instead, the Rayleigh scattering approach is used for the simplicity and efficiency necessary for the data assimilation purpose. The limitation of this assumption is the overestimation of the radar cross section for large hailstones and, therefore, the somewhat overestimation of reflectivity. The non-Rayleigh scattering effect will be included in future studies when feasible.

After performing integration over the exponential DSD, (5) and (6) yield simple forms of rain reflectivities at horizontal and vertical polarizations, as follows (Zhang et al. 2001):

$$
Z_{h, r}=\frac{4 \lambda^{4} \alpha_{r a}^{2} N_{0 r}}{\pi^{4}\left|K_{w}\right|^{2}} \Lambda_{r}^{-\left(2 \beta_{r a}+1\right)} \Gamma\left(2 \beta_{r a}+1\right)\left(\mathrm{mm}^{6} \mathrm{~m}^{-3}\right)
$$

and

$$
Z_{v, r}=\frac{4 \lambda^{4} \alpha_{r b}^{2} N_{0 r}}{\pi^{4}\left|K_{w}\right|^{2}} \Lambda_{r}^{-\left(2 \beta_{r b}+1\right)} \Gamma\left(2 \beta_{r b}+1\right)\left(\mathrm{mm}^{6} \mathrm{~m}^{-3}\right),
$$

where $\lambda$ is the radar wavelength, which is approximately $10.7 \mathrm{~cm}$ for the WSR-88D radars. The default value for the intercept parameter for rain in the LFO83 microphysics scheme is $N_{0 r}=8 \times 10^{6} \mathrm{~m}^{-4}$, but other values can be used (see discussion in Tong and Xue 2008). The slope parameter $\Lambda_{r}$ can be diagnosed from the rain mixing ratio once the intercept parameter is specified. Here $K_{w}=0.93$ is the dielectric factor for water and $\Gamma(.$.$) is the complete gamma function.$

Integrals for other species in the same way are straightforward. For completeness, they are listed below:

$$
Z_{h, x}=\frac{2880 \lambda^{4} N_{0 x}}{\pi^{4}\left|K_{w}\right|^{2}} \Lambda_{x}^{-7}\left(A \alpha_{x a}^{2}+B \alpha_{x b}^{2}+2 C \alpha_{x a} \alpha_{x b}\right)
$$

and

$$
Z_{v, x}=\frac{2880 \lambda^{4} N_{0 x}}{\pi^{4}\left|K_{w}\right|^{2}} \Lambda_{x}^{-7}\left(B \alpha_{x a}^{2}+A \alpha_{x b}^{2}+2 C \alpha_{x a} \alpha_{x b}\right) .
$$

The reflectivities in the linear scale for different species are combined to give logarithmic reflectivity at the horizontal and vertical polarizations $\left(Z_{H}\right.$ and $Z_{V}$, respectively) and differential reflectivity $\left(Z_{\mathrm{DR}}\right)$ as

$$
\begin{aligned}
Z_{H}= & 10 \log _{10}\left(Z_{h, r}+Z_{h, \mathrm{rs}}+Z_{h, \mathrm{ds}}+Z_{h, \mathrm{rh}}+Z_{h, \mathrm{dh}}\right) \\
& (\mathrm{dB} Z), \\
Z_{V}= & 10 \log _{10}\left(Z_{v, r}+Z_{v, \mathrm{rs}}+Z_{v, \mathrm{ds}}+Z_{v, \mathrm{rh}}+Z_{v, \mathrm{dh}}\right) \\
& (\mathrm{dB} Z), \text { and } \\
Z_{\mathrm{DR}}= & 10 \log _{10}\left(\frac{Z_{h}}{Z_{v}}\right) \\
= & 10 \log _{10}\left(\frac{Z_{h, r}+Z_{h, \mathrm{rs}}+Z_{h, \mathrm{ds}}+Z_{h, \mathrm{rh}}+Z_{h, \mathrm{dh}}}{Z_{v, r}+Z_{v, \mathrm{rs}}+Z_{v, \mathrm{ds}}+Z_{v, \mathrm{rh}}+Z_{v, \mathrm{dh}}}\right)
\end{aligned}
$$

$(\mathrm{dB})$. 
The reflectivity difference, another useful polarimetric variable, is defined as

$$
Z_{\mathrm{dp}}=Z_{h}-Z_{v}\left(\mathrm{~mm}^{6} \mathrm{~m}^{-3}\right) .
$$

While $Z_{\mathrm{DR}}$ contains the information about the shape of hydrometeor such as the axis ratio and size, $Z_{\mathrm{dp}}$ was proposed to handle mixed-phase precipitation concentration as dry ice phases tend to have less polarization signatures (Seliga and Bringi 1976; Straka et al. 2000; Golestani et al. 1989; Tong et al. 1998; Zrnic and Ryzhkov 1999). With the reflectivity difference, the dry snow and hail contributions are minimized so that rain is better represented. A power of 0.2 is taken of $Z_{\mathrm{dp}}$ in our data assimilation experiments so that $\left(Z_{\mathrm{dp}}\right)^{0.2}$ has a more normal-like distribution. Doing so also reduces the dynamic range of data and, therefore, $\left(Z_{\mathrm{dp}}\right)^{0.2}$ is more appropriate than $Z_{\mathrm{dp}}$ for the assimilation purpose.

The specific differential phases for the rain, rainsnow aggregate mixture, dry snow aggregate, rain-hail mixture, and dry hail are calculated, following Zhang et al. (2001), from

$$
\begin{aligned}
K_{\mathrm{DP}, x} & =\frac{180 \lambda}{\pi} \int n(D) C_{k} \operatorname{Re}\left(f_{a}-f_{b}\right) d D\left({ }^{\circ} \mathrm{km}^{-1}\right), \\
C & =\langle\cos 2 \phi\rangle=\cos 2 \bar{\phi} e^{-2 \sigma^{2}} .
\end{aligned}
$$

As above, the integral of (18) over DSD can be simplified for rain as in the following:

$$
K_{\mathrm{DP}, r}=\frac{180 \lambda}{\pi} N_{0 r} \alpha_{r k} \Lambda_{r}^{-\left(\beta_{r k}+1\right)} \Gamma\left(\beta_{r k}+1\right)\left({ }^{\circ} \mathrm{km}^{-1}\right),
$$

where nondimensional coefficients $\alpha_{r k}=1.30 \times 10^{-5}$ and $\beta_{r k}=4.63$ for rain. We can find the $\alpha_{x k}$ for $K_{\mathrm{DP}}$ from (9) to be $\alpha_{x a}-\alpha_{x b}$ for the rain-snow aggregate and rain-hail mixture. Here $\alpha_{\mathrm{ds} k}=0.3 \times 10^{-6}$ for dry snow and $\alpha_{\mathrm{dh} k}=0.26 \times 10^{-4}$ for dry hail. The $\beta_{x k}$ values for ice species and water-ice mixtures are equal to 3 . Because the $K_{\mathrm{DP}}$ calculation involves $\langle f\rangle$ while reflectivities involve $\left\langle|f|^{2}\right\rangle$ [note that the power of $D$ is 4.63 for rain and 3 for ice particles in (7) and (8), where the mass of the spherical particle is proportional to $D^{3}$ while reflectivity is often assumed to be proportional to $D^{6}$ in the Rayleigh regime], $K_{\mathrm{DP}}$ is more linearly proportional to the rainfall rate (Zrnic and Ryzhkov 1999; Bringi and Chandrasekar 2001).

The specific differential phases for different species are combined in the same manner as the reflectivity to give the total $K_{\mathrm{DP}}$ :

$$
K_{\mathrm{DP}}=K_{\mathrm{DP}, r}+K_{\mathrm{DP}, \mathrm{rs}}+K_{\mathrm{DP}, \mathrm{ds}}+K_{\mathrm{DP}, \mathrm{rh}}+K_{\mathrm{DP}, \mathrm{dh}} .
$$

\section{Applications to convective storms}

To demonstrate that the observation operators in our radar simulator produce reasonable results, they were applied to the 2D squall-line and 3D supercell storm simulations, described in section 2 . In this section, we examine the simulated radar fields on the model grid before any simulated observation error is added. The error modeling for the polarimetric variables will be discussed in Part II.

The west-east vertical cross sections of reflectivity at the horizontal polarization $\left(Z_{H}\right)$, differential reflectivity $\left(Z_{\mathrm{DR}}\right)$, reflectivity difference $\left[\left(Z_{\mathrm{dp}}\right)^{0.2}\right]$, and specific differential phase $\left(K_{\mathrm{DP}}\right)$ at $400 \mathrm{~min}$ into the $2 \mathrm{D}$ squallline simulation are shown in Fig. 3. The $0^{\circ} \mathrm{C}$ isotherm is overlaid on each plot in thick black lines. The squallline system is in its mature stage and propagates slowly eastward while the low-level flow is from the right. The low-level shear vector points rightward therefore the upshear direction is toward the left.

\section{a. Simulated radar fields for the squall-line case}

The simulated mature squall line is similar to the multicellular squall line discussed by Lin et al. (1998) and Fovell and Tan (1998) in which new cells are periodically regenerated at the leading edge of the gust front. They reach their maximum intensity while propagating rearward, and then weaken as they move into a region of weaker convective instability and turn into more stratiform clouds. Figure $3 \mathrm{a}$ shows that at the mature stage, the deepest cell, labeled $\mathrm{C} 2$, is located near $x=360 \mathrm{~km}$ and its echo top reaches nearly $14 \mathrm{~km}$. To its right are two newer cells, labeled $\mathrm{C} 3$ and $\mathrm{C} 4$, with $\mathrm{C} 3$ trying to establish itself and $\mathrm{C} 4$ still in its developing stage. To the left or rear of the deepest cell is a much weaker cell, labeled $\mathrm{C} 1$, that has passed through the most intense stages and is transitioning into more stratiform clouds (Fig. 3a). A deep column of high reflectivity of over $65 \mathrm{~dB} Z$ in the deepest convective cell, $\mathrm{C} 2$, is mainly associated with the large hail core extending to 9-km height (Fig. 4c). A small local maximum of over $70 \mathrm{~dB} Z$ at about $4-\mathrm{km}$ height (right below the $0^{\circ} \mathrm{C}$ level above the boldface $\mathrm{C}$ in Fig. 3a) where high rainwater and hail mixing ratios coexist (Figs. 4a,c). Another local maximum close to the $0^{\circ} \mathrm{C}$ level (Fig. 3a) is also associated with the coexistence of high hail and rainwater content at that location (Figs. 4a,c).

The region of high $Z_{\mathrm{DR}}$ (Fig. 3b) is located off the hail core (Fig. 4c) to its right, where rainwater content is significant (Fig. 4a). In fact, there is a local minimum, as indicated by the $Z_{\mathrm{DR}}$ "trough," at the location of low-level hail core (Fig. 3b). The region of significant 

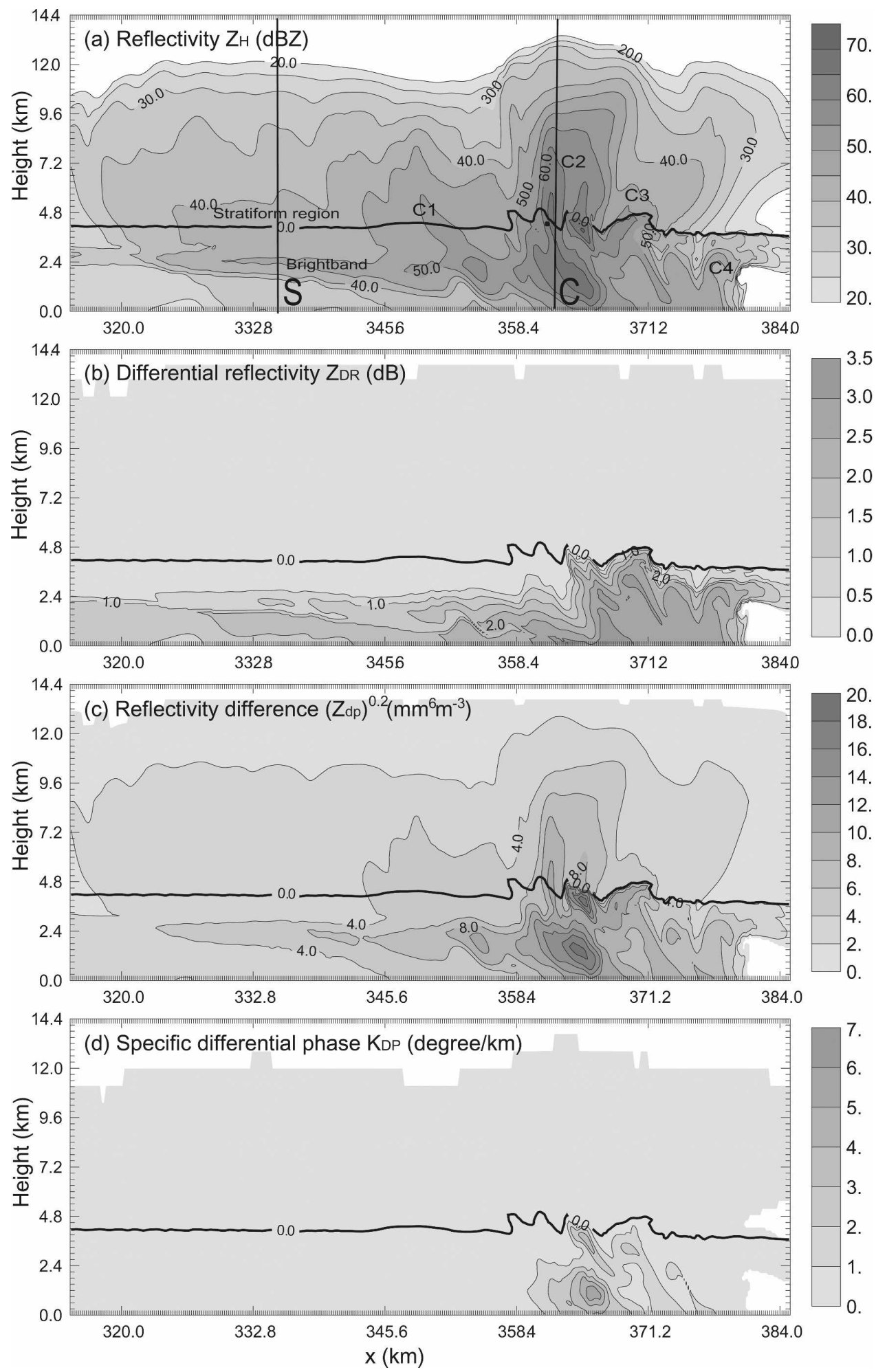

FIG. 3. The west-east vertical cross sections of the simulated (a) $Z_{H}$, (b) $Z_{\mathrm{DR}}$, (c) $Z_{\mathrm{dp}}$, and (d) $K_{\mathrm{DP}}$, at $400 \mathrm{~min}$ into the $2 \mathrm{D}$ squall-line simulation. The $0^{\circ} \mathrm{C}$ isotherms are shown as thick black lines. A sequence of cells in (a) is labeled $\mathrm{C} 1-\mathrm{C} 4$. 

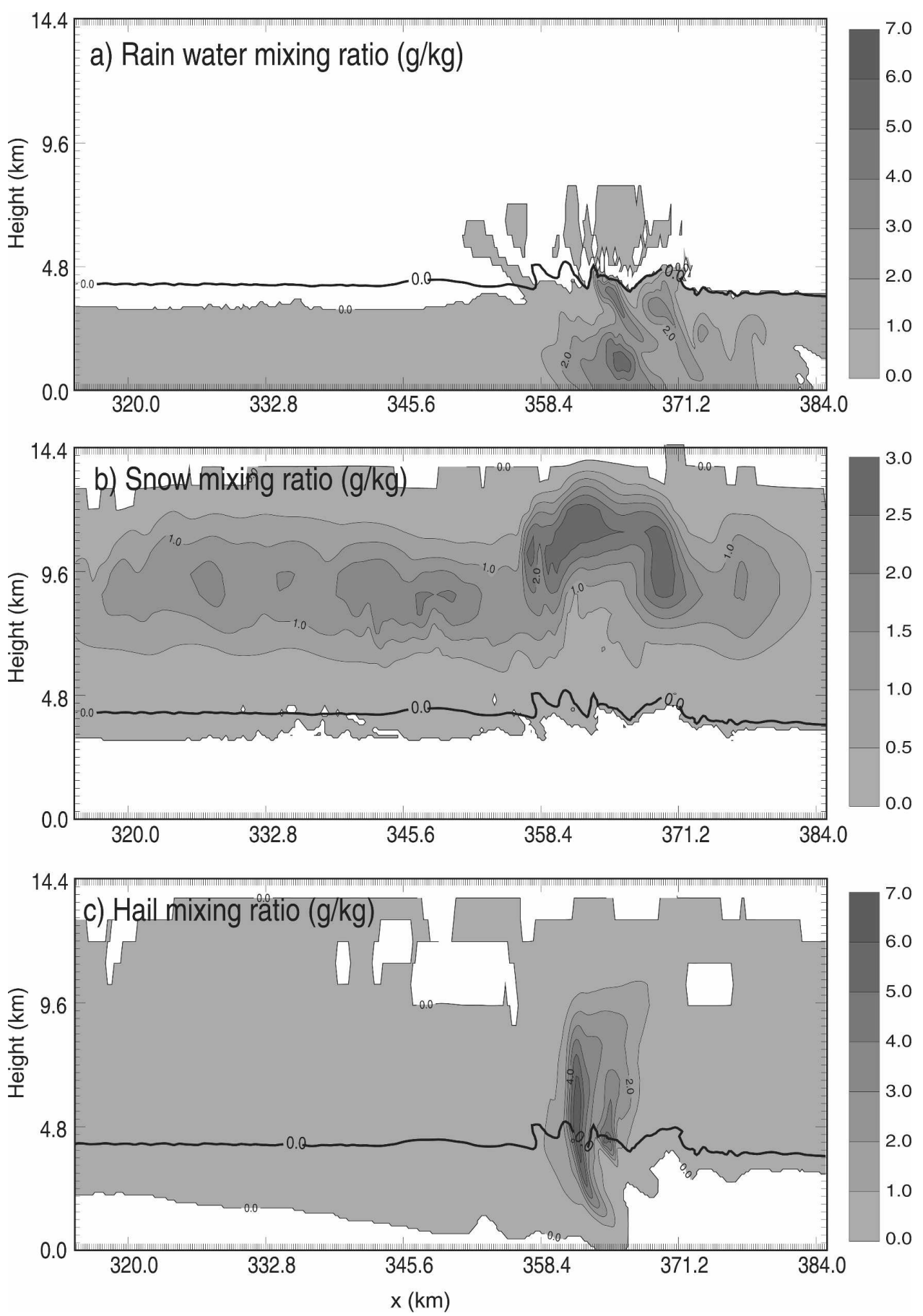

FIG. 4. As in Fig. 3, but for the model mixing ratios (a) $q_{r}$, (b) $q_{s}$, and (c) $q_{h}$.

$Z_{\mathrm{DR}}$ is also capped by the $0^{\circ} \mathrm{C}$ temperature contour (Fig. 3b). This is because that the strongest $Z_{\mathrm{DR}}$ signature is associated with rain, whose drops become flattened when their sizes increase. Because of the tumbling, statistically, hailstones appear mostly spherical to the radar beams, resulting in similar reflectivities at horizontal and vertical polarizations. The reflectivity due to hail is large, however, and the large and almost equal contributions of $Z_{h, h}$ and $Z_{v, h}$ to $Z_{H}$ and $Z_{V}$, respectively, reduce the relative importance of $Z_{h, r}$ and $Z_{v, r}$, resulting in small $Z_{\mathrm{DR}}$ values according to (16). The $Z_{\mathrm{DR}}$ values are also significant $(1.5 \sim 2.0 \mathrm{~dB})$ in a horizontally elongated region below the bright band in the stratiform precipitation region. Again, this is a re- 
gion where rainwater dominates, and is below the melting layer (Fig. 3a).

The $Z_{\mathrm{dp}}$ is insensitive to ice and is highly correlated with $Z_{h, r}$, showing sensitivity only to the oriented oblate raindrops so that it makes a good indicator of the presence of water within the rain-ice mixture, which enables the use of the concept of the deviation analysis from the rain line (Bringi and Chandrasekar 2001). When analyzed alone, $Z_{\mathrm{dp}}$ may be less useful because of its high proportionality to reflectivity. Figures $3 \mathrm{c}$ and $4 \mathrm{a}$ show that the $\left(Z_{\mathrm{dp}}\right)^{0.2}$ pattern agrees well with the pattern of rainwater mixing ratio below the melting layer. Snow and hail that have melted sufficiently can be seen as big raindrops to the radar. This is shown as a horizontally elongated enhanced $\left(Z_{\mathrm{dp}}\right)^{0.2}$ band, which matches well with the bright band in Fig. 3a. Among polarimetric variables, only $\left(Z_{\mathrm{dp}}\right)^{0.2}$ show some signatures above the $0^{\circ} \mathrm{C}$ level in the convective region. The $Z_{\mathrm{dp}}$ can be of moderate strength in the region with high concentration of hail, where $Z_{H}$ is large no matter the hail is dry or wet (Figs. 4a,c). However, these are rather weak signals considering the dynamic range of raw $Z_{\mathrm{dp}}$ observations before we take the power of 0.2 .

The region of high $K_{\mathrm{DP}}$ is mostly confined in the convective rain region (Fig. 3d). In fact, its pattern matches that of rainwater mixing ratio very well. This is because $K_{\mathrm{DP}}$ is not affected much by the presence of hail. Both $Z_{\mathrm{DR}}$ and $K_{\mathrm{DP}}$ signatures are rather weak and essentially uniform above the $0^{\circ} \mathrm{C}$ level.

While examining the simulated radar variables, we noticed that in the stratiform precipitation region, the actual melting level in the model is significantly offset from the $0^{\circ} \mathrm{C}$ isotherm. The level of the maximum bright band found in Fig. 3a is almost $1.7 \mathrm{~km}$ below the $0^{\circ} \mathrm{C}$ isotherm (at about $4.2 \mathrm{~km}$ ) and consequently significant $Z_{\mathrm{DR}}$ signatures are found at lower levels below the bright band. The mixing ratio fields in Fig. 4 show that rainwater does not start to appear until about $\sim 900$ $\mathrm{m}$ below the $0^{\circ} \mathrm{C}$ level, while snow manages to survive below the $0^{\circ} \mathrm{C}$ level for a similar depth. Such a discrepancy appears odd, for slowly falling snow in the stratiform precipitation region. To explain this peculiar behavior, we further investigated the microphysics scheme used in this study.

The Lin microphysics parameterization in the ARPS is based on the code from the National Aeronautics and Space Administration (NASA) Goddard Space Flight Center (GSFC; Tao and Simpson 1989). Our investigation reveals that the melting in this scheme does not occur until several degrees above $0^{\circ} \mathrm{C}$ (see Figs. 4a,b) because the potential cooling associated with the evaporation of water at the surface of ice particle exceeds the heating associated with the conduction and convection of heat to the particle from its environment [see Eq. (32) of LFO83]. Although some delay in the melting due to evaporative cooling is physical, we believe the amount of delay we are observing is too much. For instance, snow and hail do not start to melt until around $7^{\circ} \mathrm{C}$ at the location of $x=320 \mathrm{~km}$. We tested another implementation of the LFO83 ice microphysics scheme by Gilmore et al. (2004) and found the same behavior. The issue is therefore common with the Lin scheme. We found that the single-moment WRF 6-category microphysics scheme (WSM6; Hong and Lim 2006) and the Rutledge and Hobbs (1983) scheme on which WSM6 is based, do not have the same problem because they have a somewhat different treatment of the melting processes. However, they have other issues. Our initial attempts to modify the Lin scheme in this aspect did not lead to satisfactory results, and we will leave this microphysics parameterization issue for future studies because our current study is primarily focused on producing realistic radar simulations given reasonably realistic microphysical fields. On the other hand, we have a good example of how a realistic radar simulator can be used to validate model microphysics, and it will be even more valuable when we simulate and predict real cases and compare the results against real radar data.

To further examine the behaviors of our forward observation operators that include the melting model, two columns of mixing ratios are extracted at $x=362.2 \mathrm{~km}$ (labeled C in Fig. 3a) and $336 \mathrm{~km}$ (labeled S) from the simulated squall-line system, corresponding to the convective and stratiform regions, respectively. The profiles of radar variables are calculated from these mixing ratios and are shown in Figs. 5 and 6 . The $0^{\circ} \mathrm{C}$ temperature line is overlaid as a straight line on each plot.

Figure 5a shows the vertical profiles of $q_{n}, q_{s}, q_{h}, q_{\mathrm{rs}}$, and $q_{\mathrm{rh}}$ in the convective rain. This region shows the highest mixing ratio of hail. The mixed rain-snow mixing ratio $q_{\mathrm{rs}}$ reaches its maximum where the sum of the coexisting rain and snow mixing ratios has a maximum, but its peak value is so small as to be hardly identifiable in the plot.

The reflectivity at horizontal polarization incorporating our melting ice (MI) model is plotted in Fig. 5b as the solid black curve. In between the levels of $q_{r}$ and $q_{h}$ maxima, $q_{\mathrm{rh}}$ has its maximum, providing high reflectivity values that together with $q_{r}$ and $q_{h}$ yields a deep reflectivity core at the convective region. The result of a previously used simple linear interpolation (LI) model for melting-layer reflectivity (Jung et al. 2005) is also shown for comparison (dashed curve in Fig. 5b). 
a)

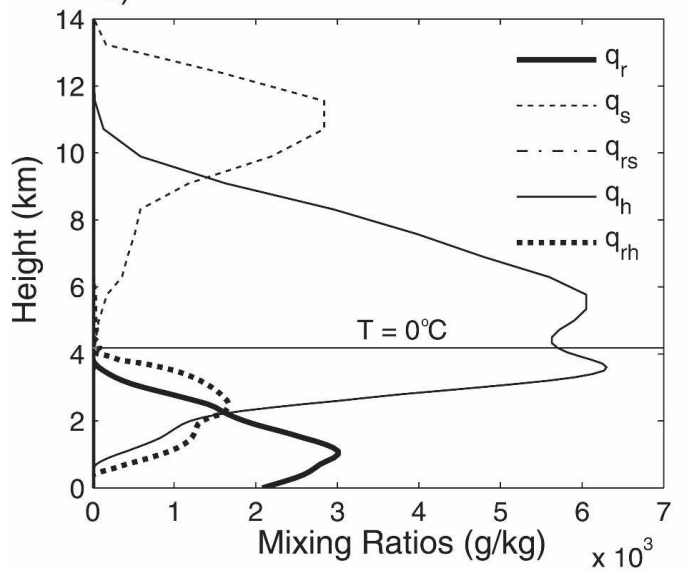

c)

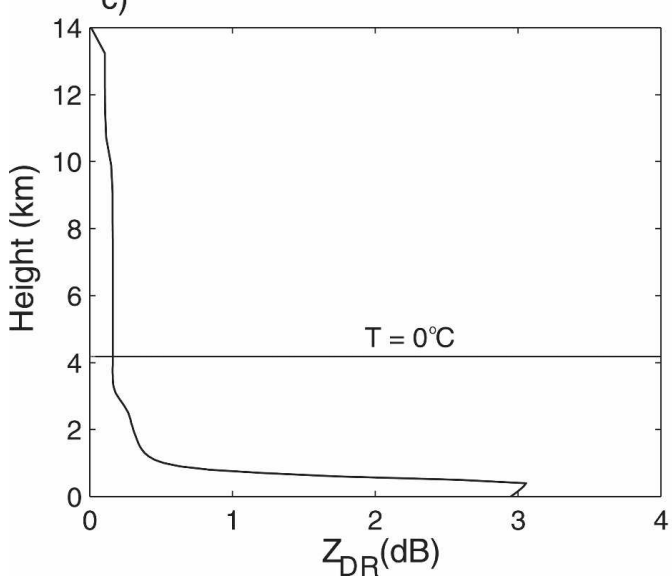

b)

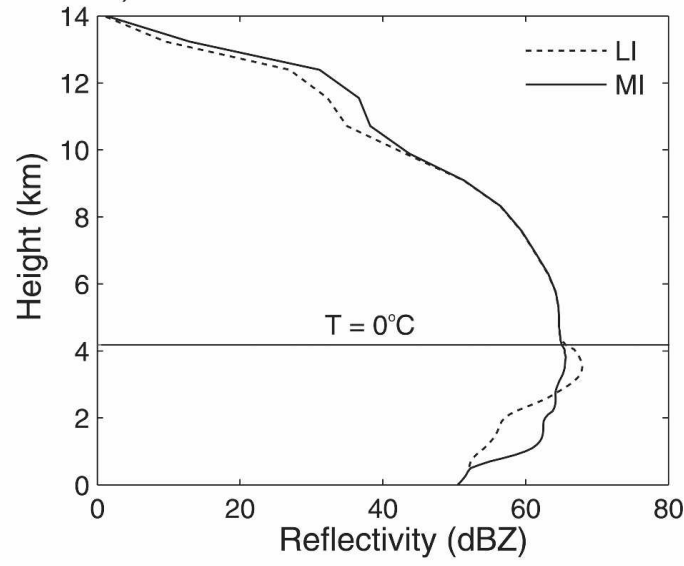

d)

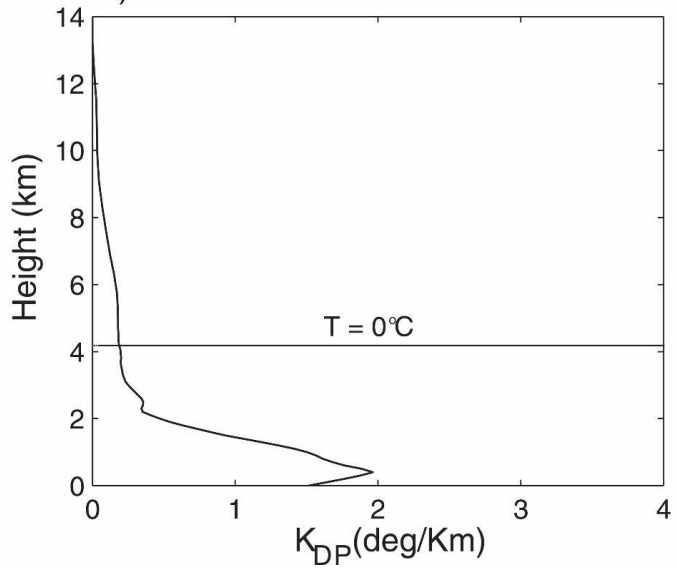

FIG. 5. A modeled vertical profile of total (in both pure and mixture forms) rainwater and total snow-hail mixing ratios and the total amount (mixing ratio) of rain and snow in a mixture form, and the simulated polarization radar signatures at the column labeled $\mathrm{C}$ in Fig. 3: (a) $q_{r}$ (thick solid), $q_{h}$ (thin solid), $q_{s}$ (thin dashed), $q_{\mathrm{rh}}$ (thick dashed), and $q_{\mathrm{rs}}$ (dash-dotted); (b) reflectivity from the LI model (dashed), reflectivity at horizontal $\left(Z_{H}\right.$, solid) polarization from the MI model; (c) $Z_{\mathrm{DR}}$; and (d) $K_{\mathrm{DP}}$. Here $q_{\mathrm{rs}}$ is on the vertical axis.

With this LI model, the snow is considered $100 \%$ wet at or above air temperatures of $0^{\circ} \mathrm{C}$ and $100 \%$ dry at or below air temperatures of $-5^{\circ} \mathrm{C}$. In between these two temperatures, the reflectivity is calculated as the weighted average of those given by the wet and dry snow formulas, with weights defined as linear functions of the temperature. The same method is applied to dry and wet hail reflectivity formulas with a corresponding air temperature range of $2.5^{\circ}$ and $-2.5^{\circ} \mathrm{C}$. When the LI model is used, the reflectivity is more directly linked to the temperature and less so to the model microphysics. Figure $5 \mathrm{~b}$ shows that the reflectivity thus calculated keeps decreasing with decreasing height below an air temperature of $2.5^{\circ} \mathrm{C}$. A maximum value is found close to the $0^{\circ} \mathrm{C}$ level while in the melting model case, the similar local enhancement is found at the deep layer of actual melting. Figures $5 \mathrm{c}$,d show the differential reflec- tivity and specific differential phase, which are found to slowly increase to their maximum values near the surface as the amount of hail decreases. Their values above $0^{\circ} \mathrm{C}$ are small.

In the stratiform region where the snow mixing ratio is the largest and is found at the upper levels, it can be seen that the current melting model produces realistic nonpolarimetric and polarimetric radar signatures with a bright band associated with the melting layer shown in both the $Z_{H}$ and $Z_{\mathrm{DR}}$ profiles (Figs. 6b,c). The reflectivity increase in the melting layer of the MI model is more prominent and shallower than that of the interpolation model. The differential reflectivity peak shows slightly below the reflectivity peak. These characteristics in reflectivity and differential reflectivity agree well with observed profiles (Fig. 8 of Brandes et al. 2004b) and the composite range-height indicator plot (Fig. 13 
a)

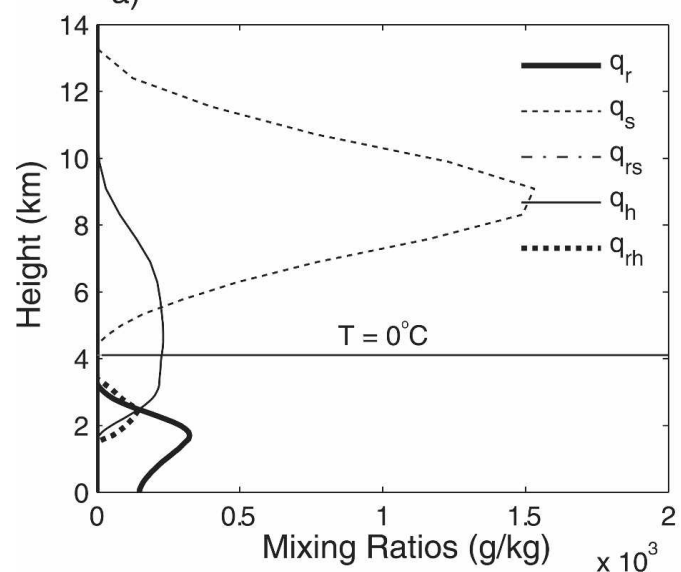

c)

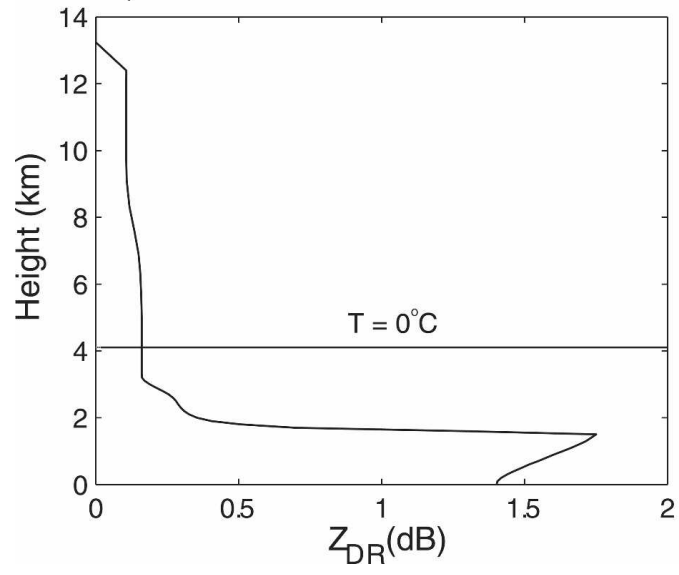

b)

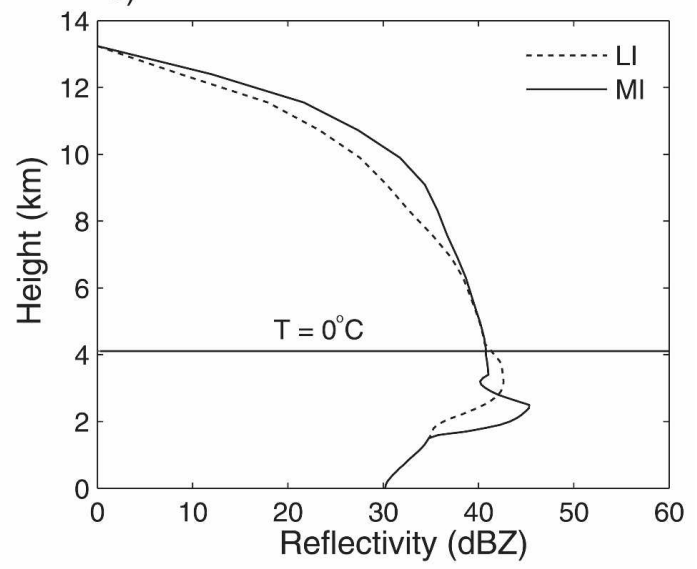

d)

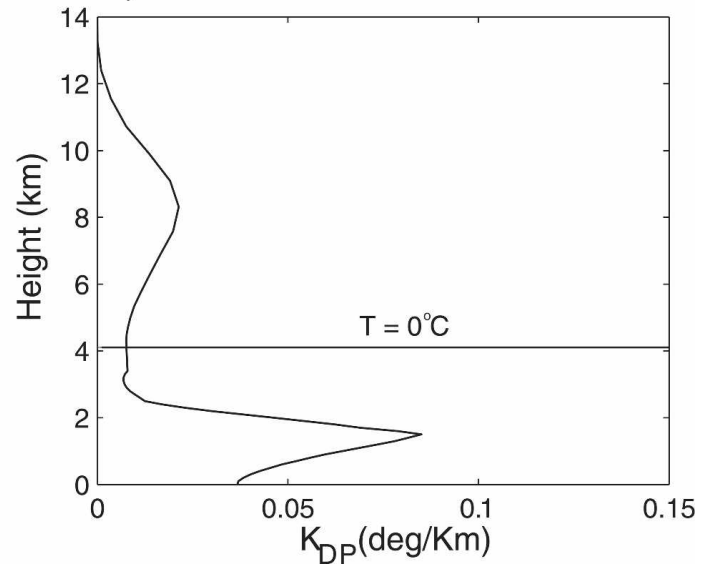

FIG. 6. As in Fig. 5, but for column $\mathrm{S}$ in Fig. 3.

of Ryzhkov et al. 2005). The better handling of the radar variables by the MI model is because of the presence of snow-rain and hail-rain mixtures and the better representation of their effects on the dielectric constants of melting snow and hail. The interpolation model does not take into account the change in the dielectric constants directly.

\section{b. Simulated radar fields for a supercell storm}

Next, we apply our observation operators to the simulated supercell storm, which will also be used in Part II to test the impact of assimilating additional polarimetric variables. Figure 7 shows the simulated polarimetric variables at the $2.5-\mathrm{km}$ altitude at $100 \mathrm{~min}$ of the storm. The storm splits at around $55 \mathrm{~min}$ into two cells; one moving toward the left of the storm motion vector that ends up near the upper-left corner of domain by $100 \mathrm{~min}$ and the other (right mover) stays close to the center of the model domain (Fig. 7a). The reflectivity pattern matches well with the hail field and the reflectivity core is collocated with hail maximum in the left-moving storm and with the common area in $q_{r}$ and $q_{h}$ maxima in the right-moving storm (Figs. 7a,b). The $Z_{\mathrm{DR}}$ shows a minimum near the reflectivity maxima, collocated with hail cores (Figs. 7b,c). This is consistent with the $Z_{\mathrm{DR}}$ hole observed in the microburst studied by Wakimoto and Bringi (1988) and the convective storm studied by Bringi et al. (1986). These observations also show that $Z_{\mathrm{DR}}$ values increase rapidly around the $Z_{\mathrm{DR}}$ hole and reach more representative values for melting ice. As discussed in the squallline case, the $K_{\mathrm{DP}}$ field is consistent with that of $q_{r}$.

Figure 8 shows the vertical structure of the supercell storm at line AB shown in Fig. 7, which passes through the updraft core and the weak echo region (WER) in the storm. In this case, the reflectivity maximum through the updraft core is found at about $4.5 \mathrm{~km}$ above the ground (Fig. 8a) because of a high concentration of hail in the melting phase there (Fig. 8f). The high reflectivity region exceeding $60 \mathrm{dBZ}$ extends to $8.5 \mathrm{~km}$, corresponding to the region of high hail. The fully developed overhang signature is consistent with the 

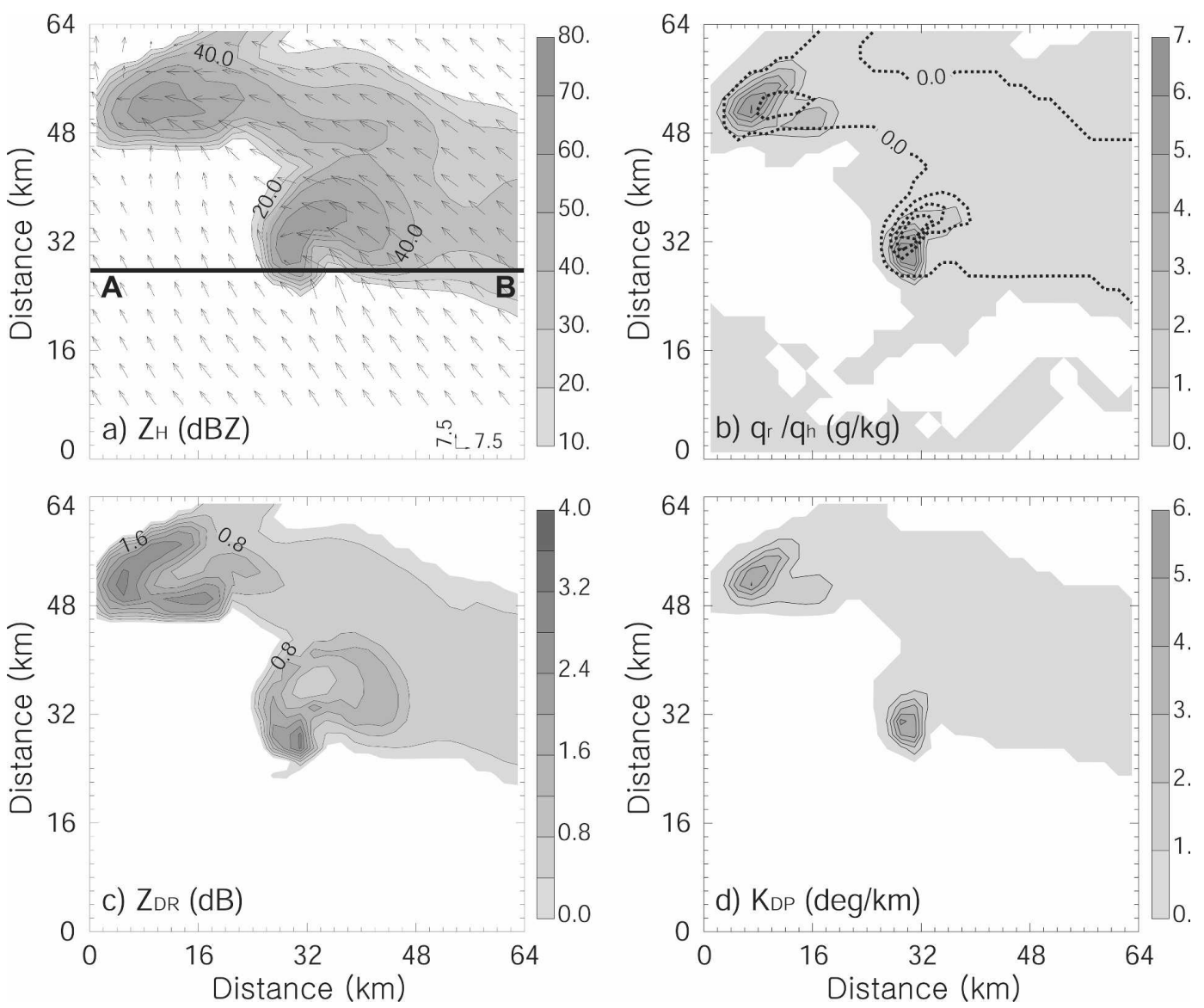

FIG. 7. (a) Horizontal wind (vectors; $\mathrm{m} \mathrm{s}^{-1}$ ) and reflectivity, $Z_{H}$; (b) rainwater $q_{r}$ (thin solid contours and shading) and $q_{h}$ (thick dotted at intervals of $1 \mathrm{~g} \mathrm{~kg}^{-1}$, starting from $0 \mathrm{~g} \mathrm{~kg}^{-1}$ ); (c) $Z_{\mathrm{DR}}$; and (d) $K_{\mathrm{DP}}$, at z $=2.5 \mathrm{~km}$ at $100 \mathrm{~min}$ of the storm.

patterns of hail and snow (Figs. 8a,e,f). It can be seen that our emulator produces reasonably weak reflectivity for dry snow compared with that for hail, as in the real storm (Figs. 8a,d,f). In contrast to the reflectivity field, $Z_{\mathrm{DR}}$ and $K_{\mathrm{DP}}$ remain low at this level in the precipitation core (Figs. 8b,c). The core of the $Z_{\mathrm{DR}}$ column (Figs. 7c and 8b) is located southwest of the center of the WER, where the reflectivity hook is located (Fig. 7a), similar to those in Fig. 2 of Hubbert et al. (1998). The top of the $Z_{\mathrm{DR}}$ column is bounded by the $0^{\circ} \mathrm{C}$ line while the observational study of Hubbert et al. (1998) shows that it rises above the $0^{\circ} \mathrm{C}$ line because raindrops or water-coated ice particles are carried by a strong updraft. In the simulated storm, supercooled water quickly converts to the ice phase so that $Z_{\mathrm{DR}}$ quickly drops accordingly. The $K_{\mathrm{DP}}$ pattern shown in Fig. 8c indicates that it has useful information content only for heavy rain, as observational and theoretical studies have shown earlier (Chandrasekar et al. 1990; Balakrishnan et al. 1989). There is hardly any $K_{\mathrm{DP}}$ signal in the light-rain region. The maximum values of specific differential phase occur where the rainwater mixing ratio is the greatest, between the $3.5-\mathrm{km}$ level and the surface (Fig. 8c). However, the maximum differential reflectivity appears near the surface because the large hail values at the higher levels reduce the relative contribution of rain, as discussed earlier for the squall-line case. Their signatures are very weak at high altitudes where the hydrometeor density is low, dielectric constant is small, and their effective shapes are spherical.

The patterns of $Z_{\mathrm{DR}}$ and $K_{\mathrm{DP}}$ are similar for different physical reasons. The $Z_{\mathrm{DR}}$ is greater where larger $q_{r}$ is found because more larger drops with more oblate shapes are expected there. The $K_{\mathrm{DP}}$ is more linearly proportional to the amount of rain as discussed in section 3c. Both $Z_{\mathrm{DR}}$ and $K_{\mathrm{DP}}$ remain low at the middle level to the right of the storm where the hail dominates among the hydrometeors (Figs. 8b,c,f). The $Z_{\mathrm{DR}}$ increases toward the surface as most hail completely melts before reaching the ground. This behavior is consistent with the $Z_{\mathrm{DR}}$ and $K_{\mathrm{DP}}$ in (16) and (19), and also agrees well with observations (Hubbert et al. 1998; Ill- 

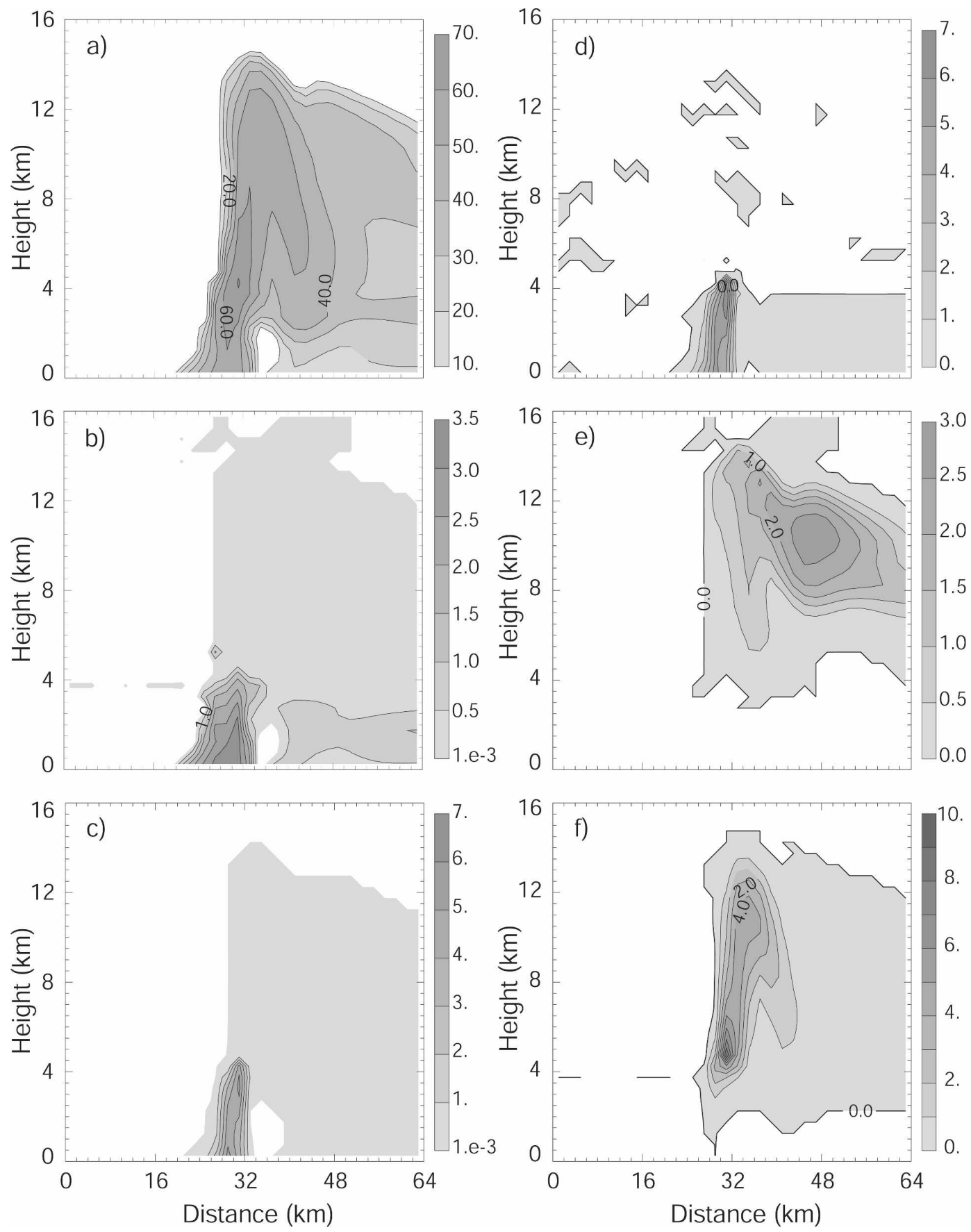

FIG. 8. The west-east vertical cross sections of simulated (a) $Z_{H}$, (b) $Z_{\mathrm{DR}}$, (c) $K_{\mathrm{DP}}$, and (d) $q_{r}$, (e) $q_{s}$, and (f) $q_{h}$ mixing ratios through the updraft core (maximum vertical velocity) of the simulated supercell storm at $100 \mathrm{~min}$, along line $\mathrm{AB}$ shown in Fig. 7a corresponding to $y=28 \mathrm{~km}$.

ingworth et al. 1987; Zrnic and Ryzhkov 1999) and with the study of Huang et al. (2005) in which a full radar scattering model is used to simulate polarimetric radar signatures of a model-simulated storm. For the purpose of data assimilation, simple formulas like those discussed in this paper have to be used. At this time, full scattering calculations are prohibitively expensive for data assimilation purposes.

\section{Summary and conclusions}

In this paper, the forward observation operators that link model state variables with polarimetric radar mea- 
surements are developed based on scattering calculations with the T-matrix method for rain and the Rayleigh scattering approximation for snow aggregates and hail. These operators, together with proper handling of the radar beam geometry and beam-weighting functions, form a radar simulator. The operators are developed mainly for the purpose of assimilating the corresponding measurements into storm-scale numerical models; at the same time, they can be used to verify model predictions against radar observations.

The radar measurements considered include the reflectivities of the horizontal and vertical polarizations $\left(Z_{H}\right.$ and $\left.Z_{V}\right)$, differential reflectivity $\left(Z_{\mathrm{DR}}\right)$, reflectivity difference $\left(Z_{\mathrm{dp}}\right)$, and specific differential phase $\left(K_{\mathrm{DP}}\right)$. The work is necessitated by the unavailability of existing observation operators for most of the polarimetric variables that are efficient for data assimilation purposes and make use of all microphysical information available in a numerical model. Because of the lack of information in typical bulk microphysics schemes on the liquid water fraction of ice, a new melting model is developed that assumes a function for the water fraction based on known rainwater, snow, and hail mixing ratios. The effects of varying density due to the melting snow and hail are also included.

The observation operators developed are tested with a model-simulated mature squall-line system that includes both deep convection and stratiform precipitation regions, and a supercell storm with high hail content. Realistic nonpolarimetric and polarimetric radar signatures are produced in the simulated fields, including a bright band and realistic spatial distributions of $Z_{\mathrm{DR}}$ and $K_{\mathrm{DP}}$ signatures. The simulated radar fields suggest a problem with the treatment of snow and hail melting processes in the Lin-type microphysics scheme, which will be examined in more depth in the future. Additional future work will include the simulation of additional polarimetric parameters such as the correlation coefficient between signals of horizontal and vertical polarizations.

Our simulated reflectivity seems generally higher than the observed one for ice phases. This is partly because non-Rayleigh scattering effects have been neglected in the calculation. This could have a larger impact in the convective rain than in the stratiform rain. The fixed DSD intercept parameter of hail is probably responsible for high reflectivity in the stratiform precipitation region where we expect mostly small ice particles. The hail intercept parameter is two orders of magnitude smaller than those of rain and snow and can lead to high reflectivity. Last, the lack of raindrop breakup, which is neglected in our microphysical parameterization, is another source of high reflectivity.
When the DSD is not properly truncated, a few unrealistically large drops can significantly increase reflectivity.

The observation operators have been implemented in our ensemble Kalman filter data assimilation system, and the impact of additional polarimetric measurements on the analysis of a supercell storm will be examined in Part II of this study.

Acknowledgments. The authors thank Dr. Alexander Ryzhkov for valuable discussions at the early stage of this work and Daniel Dawson for providing his squallline simulation configurations. This work was primarily supported by NSF Grants EEC-0313747 and ATM0608168. Ming Xue was also supported by NSF Grants ATM-0530814, ATM-0331594, and ATM-0331756, and by Chinese Natural Science Foundation Grant 40620120437. The computations were performed at the Pittsburgh Supercomputing Center supported by NSF and at the OU Supercomputing Center for Education and Research. Suggestions and comments of anonymous reviewers improved this paper.

\section{REFERENCES}

Aydin, K., and Y. Zhao, 1990: A computational study of polarimetric radar observables in hail. IEEE Trans. Geosci. Remote Sens., 28, 412-422.

Balakrishnan, N., D. Zrnić, J. Goldhirsh, and J. Rowland, 1989: Comparison of simulated rain rates from disdrometer data employing polarimetric radar algorithms. J. Atmos. Oceanic Technol., 6, 476-486.

Beard, K. V., and A. R. Jameson, 1983: Raindrop canting. J. Atmos. Sci., 40, 448-454.

Brandes, E. A., J. Vivekanandan, J. D. Tuttle, and C. J. Kessinger, 1995: A study of thunderstorm microphysics with multiparameter radar and aircraft observations. Mon. Wea. Rev., 123, 3129-3143.

_- G. Zhang, and J. Vivekanandan, 2002: Experiments in rainfall estimation with a polarimetric radar in a subtropical environment. J. Appl. Meteor., 41, 674-685.

,-- , and - , 2004a: Comparison of polarimetric radar drop size distribution retrieval algorithms. J. Atmos. Oceanic Technol., 21, 584-598.

,,-- and,$- 2004 \mathrm{~b}$ : Drop size distribution retrieval with polarimetric radar: Model and application. J. Appl. Meteor., 43, 461-475.

Bringi, V. N., and V. Chandrasekar, 2001: Polarimetric Doppler Weather Radar: Principles and Applications. Cambridge University Press, 662 pp.

_ _, J. Vivekanandan, and J. D. Tuttle, 1986: Multiparameter radar measurements in Colorado convective storms. Part II: Hail detection studies. J. Atmos. Sci., 43, 2564-2577.

Caumont, O., and Coauthors, 2006: A radar simulator for highresolution nonhydrostatic models. J. Atmos. Oceanic Technol., 23, 1049-1067.

Chandrasekar, V., V. N. Bringi, N. Balakrishnan, and D. S. Zrnic', 1990: Error structure of multiparameter radar and surface measurements of rainfall. Part III: Specific differential phase. J. Atmos. Oceanic Technol., 7, 621-629. 
Doviak, R., and D. Zrnić, 1993: Doppler Radar and Weather Observations. 2nd ed. Academic Press, $562 \mathrm{pp}$.

Ferrier, B. S., 1994: A double-moment multiple-phase four-class bulk ice scheme. Part I: Description. J. Atmos. Sci., 51, 249280.

Fovell, R. G., and P.-H. Tan, 1998: The temporal behavior of numerically simulated multicell-type storms. Part II: The convective cell life cycle and cell regeneration. Mon. Wea. Rev., 126, 551-577.

Gilmore, M. S., J. M. Straka, and E. N. Rasmussen, 2004: Precipitation and evolution sensitivity in simulated deep convective storms: Comparisons between liquid-only and simple ice and liquid phase microphysics. Mon. Wea. Rev., 132, 1897-1916.

Golestani, Y., V. Chandrasekar, and V. N. Bringi, 1989: Intercomparison of multiparameter radar measurements. Preprints, 24th Conf. on Radar Meteorology, Tallahassee, FL, Amer. Meteor. Soc., 309-314.

Green, A. V., 1975: An approximation for shape of large raindrops. J. Appl. Meteor., 14, 1578-1583.

Haase, G., and S. Crewell, 2000: Simulation of radar reflectivity using a mesoscale weather forecast model. Water Resour. Res., 36, 2221-2231.

Hendry, A., and G. C. McCormick, 1976: Radar observations of the alignment of precipitation particles by electrostatic fields in thunderstorms. J. Geophys. Res., 81, 5353-5357.

Hong, S.-Y., and J.-O. J. Lim, 2006: The WRF single-moment 6-class microphysics scheme (WSM6). J. Korean Meteor. Soc., 42, 129-151.

$\mathrm{Hu}$, M., M. Xue, and K. Brewster, 2006a: 3DVAR and cloud analysis with WSR-88D level-II data for the prediction of Fort Worth tornadic thunderstorms. Part I: Cloud analysis and its impact. Mon. Wea. Rev., 134, 675-698.

,-- J. Gao, and K. Brewster, 2006b: 3DVAR and cloud analysis with WSR-88D level-II data for the prediction of Fort Worth tornadic thunderstorms. Part II: Impact of radial velocity analysis via 3DVAR. Mon. Wea. Rev., 134, 699-721.

Huang, G.-J., V. N. Bringi, S. van den Heever, and W. Cotton, 2005: Polarimetric radar signatures from RAMS microphysics. Preprints, 32nd Int. Conf. on Radar Meteorology, Albuquerque, NM, Amer. Meteor. Soc., P11R.6. [Available online at http://ams.confex.com/ams/pdfpapers/96261.pdf.]

Hubbert, J., V. N. Bringi, L. D. Carey, and S. Bolen, 1998: CSUCHILL Polarimetric radar measurements from a severe hail storm in eastern Colorado. J. Appl. Meteor., 37, 749-775.

Illingworth, A. J., J. W. F. Goddard, and S. M. Cherry, 1987: Polarization radar studies of precipitation development in convective storms. Quart. J. Roy. Meteor. Soc., 113, 469-489.

Jung, Y., M. Xue, and J. M. Straka, 2005: Assimilation of polarimetric radar data using ensemble Kalman filter: Experiments with simulated data. Preprints, 21st Conf. on Weather Analysis and Forecasting/17th Conf. on Numerical Weather Prediction, Washington, DC, Amer. Meteor. Soc., 13A.3. [Available online at http://ams.confex.com/ams/pdfpapers/94253.pdf.]

, - - G. Zhang, and J. Straka, 2008: Assimilation of simulated polarimetric radar data for a convective storm using the ensemble Kalman filter. Part II: Impact of polarimetric data and storm analysis. Mon. Wea. Rev., 136, 2246-2260.

Kalnay, E., 2002: Atmospheric Modeling, Data Assimilation, and Predictability. Cambridge University Press, $341 \mathrm{pp}$.

Knight, N. C., 1986: Hailstone shape factor and its relation to radar interpretation of hail. J. Climate Appl. Meteor., 25, 1956-1958.

Lin, Y.-L., R. D. Farley, and H. D. Orville, 1983: Bulk parameter- ization of the snow field in a cloud model. J. Climate Appl. Meteor., 22, 1065-1092.

_, R. L. Deal, and M. S. Kulie, 1998: Mechanisms of cell regeneration, development, and propagation within a twodimensional multicell storm. J. Atmos. Sci., 55, 1867-1886.

Matson, R. J., and A. W. Huggins, 1980: The direct measurement of the sizes, shapes, and kinematics of falling hailstones. $J$. Atmos. Sci., 37, 1107-1125.

Maxwell-Garnett, J. C., 1904: Colors in metal glasses and in metallic films. Philos. Trans. Roy. Soc. London, A203, 385-420.

May, R. M., M. I. Biggerstaff, and M. Xue, 2007: A Doppler radar emulator with an application to the detectability of tornadic signatures. J. Atmos. Oceanic Technol., 24, 1973-1996.

Otkin, J. A., D. J. Posselt, E. R. Olson, H.-L. Huang, J. E. Davies, J. Li, and C. S. Velden, 2007: Mesoscale numerical weather prediction models used in support of infrared hyperspectral measurement simulation and product algorithm development. J. Atmos. Oceanic Technol., 24, 585-601.

Ray, P. S., B. Johnson, K. W. Johnson, J. S. Bradberry, J. J. Stephens, K. K. Wagner, R. B. Wilhelmson, and J. B. Klemp, 1981: The morphology of severe tornadic storms on 20 May 1977. J. Atmos. Sci., 38, 1643-1663.

Rotunno, R., J. B. Klemp, and M. L. Weisman, 1988: A theory for strong long-lived squall lines. J. Atmos. Sci., 45, 463-485.

Rutledge, S. A., and P. V. Hobbs, 1983: The mesoscale and microscale structure and organization of clouds and precipitation in midlatitude cyclones. Part VIII: A model for the feeder-seeder process in warm frontal rainbands. J. Atmos. Sci., 40, 1185-1206.

Ryzhkov, A. V., D. S. Zrnic, and B. A. Gordon, 1998: Polarimetric method for ice water content determination. J. Appl. Meteor., 37, 125-134.

, - - J. C. Hubbert, V. N. Bringi, J. Vivekanandan, and E. A. Brandes, 2002: Polarimetric radar observations and interpretation of co-cross-polar correlation coefficients. J. Atmos. Oceanic Technol., 19, 340-354.

— S. E. Giangrande, and R. J. Schuur, 2005: Rainfall estimation with a polarimetric prototype of WSR-88D. J. Appl. Meteor., 44, 502-515.

Seliga, T. A., and V. N. Bringi, 1976: Potential use of radar differential reflectivity measurements at orthogonal polarizations for measuring precipitation. J. Appl. Meteor., 15, 59-76.

Smith, P. L., 1984: Equivalent radar reflectivity factors for snow and ice particles. J. Climate Appl. Meteor., 23, 1258-1260.

Smith, P. L., Jr., C. G. Myers, and H. D. Orville, 1975: Radar reflectivity factor calculations in numerical cloud models using bulk parameterization of precipitation processes. J. Appl. Meteor., 14, 1156-1165.

Straka, J. M., D. S. Zrnić, and A. V. Ryzhkov, 2000: Bulk hydrometeor classification and quantification using polarimetric radar data: Synthesis of relations. J. Appl. Meteor., 39, 13411372.

Tao, W.-K., and J. Simpson, 1989: Modeling study of a tropical squall-type convective line. J. Atmos. Sci., 46, 177-202.

Thorpe, A. J., M. J. Miller, and M. W. Moncrieff, 1982: Twodimensional convection in non-constant shear: A model of midlatitude squall lines. Quart. J. Roy. Meteor. Soc., 108, 739 762.

Tong, H., V. Chandrasekar, K. R. Knupp, and J. Stalker, 1998: Multiparameter radar observations of time evolution of convective storms: Evaluation of water budgets and latent heating rates. J. Atmos. Oceanic Technol., 15, 1097-1109.

Tong, M., and M. Xue, 2005a: Simultaneous retrieval of micro- 
physical parameters and atmospheric state variables with radar data and ensemble Kalman filter method. Preprints, 21st Conf. on Weather Analysis and Forecasting/17th Conf. on Numerical Weather Prediction, Washington, DC, Amer. Meteor. Soc., P1.30. [Available online at http://ams.confex.com/ams/ pdfpapers/95042.pdf.]

, and — 2005b: Ensemble Kalman filter assimilation of Doppler radar data with a compressible nonhydrostatic model: OSS experiments. Mon. Wea. Rev., 133, 1789-1807.

$\longrightarrow$, and - 2008: Simultaneous estimation of microphysical parameters and atmospheric state with simulated radar data and ensemble square-root Kalman filter. Part I: Sensitivity analysis and parameter identifiability. Mon. Wea. Rev., 136, 1630-1648.

Vivekanandan, J., R. Raghavan, and V. N. Bringi, 1993: Polarimetric radar modeling of mixtures of precipitation particles. IEEE Trans. Geosci. Remote Sens., 31, 1017-1030.

_ , V. N. Bringi, M. Hagen, and G. Zhang, 1994: Polarimetric radar studies of atmospheric ice particles. IEEE Trans. Geosci. Remote Sens., 32, 1-10.

Wakimoto, R. M., and V. N. Bringi, 1988: Dual-polarization observations of microbursts associated with intense convection: The 20 July storm during the MIST project. Mon. Wea. Rev., 116, 1521-1539.

Weisman, M. L., and J. B. Klemp, 1982: The dependence of numerically simulated convective storms on vertical wind shear and buoyancy. Mon. Wea. Rev., 110, 504-520.
Xue, M., 2002: Density currents in shear flows: Effects of rigid lid and cold-pool internal circulation, and application to squall line dynamics. Quart. J. Roy. Meteor. Soc., 128, 47-74.

$\longrightarrow$, K. K. Droegemeier, and V. Wong, 2000: The Advanced Regional Prediction System (ARPS) - A multiscale nonhydrostatic atmospheric simulation and prediction tool. Part I: Model dynamics and verification. Meteor. Atmos. Phys., 75, 161-193.

— , and Coauthors, 2001: The Advanced Regional Prediction System (ARPS) - A multiscale nonhydrostatic atmospheric simulation and prediction tool. Part II: Model physics and applications. Meteor. Atmos. Phys., 76, 143-165.

—, D.-H. Wang, J.-D. Gao, K. Brewster, and K. K. Droegemeier, 2003: The Advanced Regional Prediction System (ARPS), storm-scale numerical weather prediction and data assimilation. Meteor. Atmos. Phys., 82, 139-170.

— - M. Tong, and K. K. Droegemeier, 2006: An OSSE framework based on the ensemble square-root Kalman filter for evaluating impact of data from radar networks on thunderstorm analysis and forecast. J. Atmos. Oceanic Technol., 23, $46-66$.

Zhang, G., J. Vivekanandan, and E. Brandes, 2001: A method for estimating rain rate and drop size distribution from polarimetric radar measurements. IEEE Trans. Geosci. Remote Sens., 39, 830-841.

Zrnić, D. S., and A. V. Ryzhkov, 1999: Polarimetry for weather surveillance radars. Bull. Amer. Meteor. Soc., 80, 389-406. 